\title{
Indigenous Communities and Community-Engaged Research: Opportunities and Challenges
}

\author{
Catherine McGregor, Onowa McIvor, Patricia Rosborough
}

\begin{abstract}
As the inaugural issue of The Engaged Scholar Journal made apparent, while there is significant evidence that community-engaged scholarship has reached a critical mass in Canadian institutions, many important junctures still need to be explored. One such issue is the recognition of Indigenous community-engaged scholarship. Working from an appreciative stance, the three authors of this article explore how existing communityengaged scholarship theory intersects with their own experiences as academics-teasing out some of the potentialities and tensions that exist in the lived spaces where communityengagement thrives, amidst the boundaries of institutional tenure and promotion policies. The article also explores what kinds of practices or policies might be usefully considered by institutions, particularly around how to engage in more inclusive processes of scholarly recognition. We argue it is possible to embrace tools that create reciprocal, respectful and meaningful relationships between Indigenous and non-Indigenous peoples who share deeply held beliefs in the power of research to alter lives and communities in powerful ways.
\end{abstract}

KeYWords Decolonization; Indigenous scholarship; tenure and promotion; community-engaged scholarship; scholarly reconciliation

\begin{abstract}
'We want to believe that it's true.... That adopting community-engaged scholarship criteria in our institution will mean our community work is recognized and valued. The work we do is so important in effecting changes in our communities — and central to how we understand ourselves as scholars. Yet the stories and experiences of others we work and talk with don't reflect that intention. We have allies - like you, Catherine. Yet as pre-tenured academics, and Indigenous women, can we afford to take the risk? And if we don't, will our communities understand?" 1
\end{abstract}

We write this article as a shared endeavour: one faculty member with tenure and two others, aspiring to that status. We write from the position of strong commitments to education, and Indigenous education in particular. We write as faculty members who value and promote partnerships between Indigenous communities and the university. We know we have many

\footnotetext{
1 This fictionalized opening scenario reflects the thoughts and ideas of the authors who worked together to conceptualize
} and write this article. 
privileges afforded to us through this work, and it is from these positions we seek to effect changes in practices and processes that benefit our communities. Yet the discourses and practices of our institution and the socio-political culture of the academy also shape us. In this paper, we explore how these positions and positioning affect our efforts to perform in these dual, and often competing contexts.

According to Indigenous protocols, we will begin by introducing ourselves more fully. Catherine McGregor is an Indigenous ally, a queer woman and white settler who has been a visitor to Coast Salish territories for much of her life. Her disciplinary background is in social justice leadership. Trish (Patricia) Rosborough is from the Kwakiutl First Nation on Vancouver Island. She is an assistant professor in the Indigenous Education program at the University of Victoria and the former Director of Aboriginal Education for the BC Ministry of Education. Her disciplinary focus is Indigenous Language Revitalization and Indigenous Language Education. Onowa McIvor is from Norway House Cree First Nation in northern Manitoba. She is an assistant professor and the Director of Indigenous Education at the University of Victoria; she was also one of the founding members of this academic unit. Her disciplinary focus is both Indigenous Language Revitalization and Indigenous Education writ large. We decided to write a paper for this special edition of Engaged Scholar Journal: Community-Engaged Research, Teaching and Learning as we felt our stories as early career Indigenous scholars within a Western European tenure system were important ones to share, particularly in the context of reconciliation. We will also explore our recent experiences of working together on a review of the Bachelor of Education in Indigenous Language Revitalization (BEDILR). While we experienced moments of incredible excitement because of the impact this program is having on/with our community partners, we also experienced frustration and anxiety because of the tools that are used institutionally to measure this and other scholarly work. Our experiences will, we believe, provide evidence of the vitally important work yet to be done to support Indigenous, community-engaged scholars. In telling our story, we weave together the scholarly literature on community-engaged scholarship and reports on how Canadian institutions are revising their assessment and impact policies, and then consider the contradictions that emerge when the literature and reports are examined through Indigenous ways of knowing and calls for decolonizing the academy. We share some examples of how these contradictions have played out for us in our work, and then conclude with some observations and potential implications for university administrators and policy makers.

\section{Community-Engaged Scholarship: Conceptual Challenges}

There have been considerable efforts over the last decade to define what is meant by communityengaged scholarship; while there is not always agreement, many institutions reference the Carnegie Foundation's definition of engagement:

[T] he collaboration between institutions of higher education and their larger communities (local, regional/state, national and global) for the mutually beneficial exchange of knowledge and resources in a context of partnership and reciprocity... 
[designed] to enrich scholarship, research, and creative activity; enhance curriculum, teaching and learning; prepare educated, engaged citizens; strengthen democratic values and civic responsibility; address critical societal issues; and contribute to the public good. (Carnegie Foundation, 2015, para 8)

While references to reciprocity are key, the need to acknowledge power and resource differentials is also important (Jackson, 2014). However, this notion of a university as partner in the creation of a richer, more engaged and socially just world is a fundamental value evident in these expressions of the need for community-engaged scholarship.

There is an increasing level of support for this kind of activity; rhetorical and public expressions of support for community engagement proliferate at the strategic level within Canadian research institutions (see for example, Jackson, 2014; Wenger, Hawkins \& Seifer, 2012). However, tensions and challenges emerge within institutional policies and practices, particularly when one considers how deeply scholarship is embedded in the process of tenure and promotion. While definitions of community-engaged scholarship seek to expand the horizon of what counts as legitimate and worthy academic activity - institutional practices and institutional players may still prioritize and privilege traditional forms of scholarship, such as blind, peer-reviewed papers, and indexed and ranked journal tables (Ellingson \& Quinlan, 2012). Another limitation comes from characterizations of community-engaged scholarship using Western notions of problem definition and investigation represented thusly:

\begin{abstract}
The obstacle to engaged-community research most frequently mentioned is the typical reward system, which puts the highest value on individual in-depth, theory-based research that expands knowledge within a specific field. In that system, the often more interdisciplinary, collaborative, and real-world applied character of engagedcommunity research, where a specific problem is the primary focus, is looked down upon or not considered when it comes to determining tenure and promotion. (Scott, 2007, p. 9)
\end{abstract}

In this example, we can see how the author creates a space for an alternative to disciplinary focused knowledge, but still assumes that scholarship is a function of solving research problems. Thereby, even when the scope of the terrain is widened, scholarship remains grounded in traditional, Eurocentric notions of what kinds of research matter. Such characterizations continue to marginalize forms of community engagement that might emerge from Indigenous epistemologies, conceptualizations of relationality or Indigenous worldviews.

Understanding the limitations of many tenure and promotion criteria, some academic institutions are seeking ways to 'measure differently' and so, new rubrics or practices emerge (for example, the University of Regina, University of Victoria, and University of Alberta models of Community Engaged Scholarship (CES) are each identified in an institutional policy review conducted by Barreno, Elliott, Madueke and Sarny, 2013). Yet too often it appears that the assessment is based on either personal advocacy or the support of formal leaders 
at the faculty level who promote and support individual scholars and CES. In many cases, systems continue to rank activity on a comparative basis; some categories include things such as the degree of impact, capacity for influencing other colleagues, community decision makers, or research activity (see for example, Jordan's (2006) Developing Criteria for Engaged Scholars for Promotion or Tenure). The point here is that in attempting to create a more inclusive space for community-engaged scholarship, many alternative approaches take up traditional discourses of measurement and continue to valorize processes of ranking and labelling.

The final conceptual challenge we touch upon is the broadly inclusive ways in which community-engaged scholarship is defined. In reviewing the literature, we did not find many which referenced specifically Indigenous communities, nor the marginalization of Indigenous scholars in post-secondary institutions. Additionally, we saw no evidence that these discussions about community-engaged scholarship sought to engage with Indigenous scholars about their specific needs or desires for better framing of community-engaged scholarship. It was only when we broadened our search to include "Indigenous research" that we were able to find work that substantially discussed the complexities of Indigenous, community-engaged research. The primary tension identified was the differing value universities and communities place on outcomes. As noted above, the university setting valorizes particular forms of knowledge creation (publications in particular) while the community more highly values efforts that seek to assert and regain control of their histories, communities and languages and lead to action that dismantles community structures (Gaudry, 2015). Gaudry characterizes the university models of research as "extractive" (p. 245) putting the advancement of knowledge ahead of local community needs. Instead he argued for what he described as insurgent research: "Insurgent research is all about relationships, so it directs its efforts at those who will most likely produce real and lasting change: Indigenous communities" (p. 248). This focus is core to what we will describe next: the call to Indigenize and decolonize the academy.

\section{Indigenizing and Decolonizing Approaches to Community-Engaged Scholarship}

Like Mihesuah and Wilson (2004), we begin from the premise that "the academy is worth Indigenizing because something productive will happen as a consequence" (p. 5). Indeed we think the processes of Indigenizing the academy parallel many of the goals that characterize those who work in the field of community-engaged scholarship-both seek to challenge dominant, normative practices that marginalize, essentialize, and de-legitimize the work of some while privileging others.

Marie Battiste, a seminal Indigenous education scholar from Canada articulately explains:

Indigenous scholars discovered that Indigenous knowledge is far more than the binary opposite of western knowledge. As a concept, Indigenous knowledge benchmarks the limitations of Eurocentric theory-its methodology, evidence, and conclusions. It reconceptualizes the resilience and self-reliance of Indigenous peoples, and underscores the importance of their own philosophies, heritages, and educational processes. Indigenous knowledge fills the ethical and knowledge gaps in Eurocentric 
education, research and scholarship. By animating the voices and experiences of the cognitive "other" and integrating them into the educational process, it creates a new, balanced center and a fresh vantage point from which to analyze Eurocentric education and its pedagogies. (2002, p. 7)

Decolonization therefore requires a paradigm shift, a new way of thinking; it is a critical response to the history of colonialism, imperialism, and Euro-centrism that has dominated post-secondary institutions for many years. It requires the work of both Indigenous and nonIndigenous academics, as we seek to find ways to value and recognize new forms of knowledge, ways of being, and of particular concern to this article, forms of scholarship.

\section{Potential Approaches that Decolonize Scholarly Tools of Measurement}

A number of Indigenous scholars have discussed alternatives to Western conceptions of research and scholarship. For example, Gaudry (2015) identifies four potential approaches: 1) the substitution of Indigenous worldviews as valid standards of scrutiny; 2) accessibility of research activity to communities; 3) recognition of relational forms of accountability; and 4) priority given to actions which positively affect community lives. Mihesuah (2004) argued that institutional gatekeeping is alive and well among academic institutions where individuals and institutional practices act as "sentries" and "rulers." She describes their actions as everything from accepting only "nonthreatening" Indigenous scholars who seek membership within, to undervaluing Indigenous forms of scholarship and using hiring criteria that devalues Indigenous scholars who request recognition of their responsibilities as members of Indigenous communities. The politics of being an individual who serves as "window dressing... that is universities want us, but not our opinions" (p. 44), lays bare the social, cultural and political landscape of the academy that maintains marginalization of Indigenous scholarship. Building on this, Deloria (2004) documented the "extraordinary roadblocks" to academic parity among the growing number of Indigenous scholars in the academy: "Indian scholars must spend considerably more time planning their academic futures, developing allies within academic circles, and cultivating contacts outside the institutional setting in which they find themselves" (p. 26). Additionally, the Indigenous scholar will be the one most likely to do 'double duty' as members on university committees, and to serve as "authorities" on any matter Indigenous. He also discussed community service, which, while valued among their non-Indigenous colleagues as a supplementary activity, has a completely different purpose and often with completely different outcomes and expectations for Indigenous scholars. Finally, Deloria (2004) recognized the need for Indigenous scholars to take on public debates that marginalize or maintain discriminatory beliefs as a core responsibility of their work. CavenderWilson (2004) also described this scope of work as necessary for the process of recovering Indigenous knowledges and ways of living; this revaluing of traditional Indigenous ways

...becomes a conscious political act in which we actively resist the forces of colonialism... [and] any efforts to restore our traditional ways would have to be 
matched with a strong community decolonization agenda... Through a consciously critical adaption, these ways can then provide the foundation to carry our people through the twenty-first century and beyond. (p. 72-73)

She goes on to say that documenting these processes is critically important to working as an Indigenous scholar, although such work is often undermined by traditional academic lenses which determine what matters - and mapping and reporting on decolonizing work is not respected as scholarly activity in the way it should be. Cavender-Wilson (2004) gives specific reference to local language revitalization as an exemplar of vital Indigenous community-driven work, but notes how frequently existing academic norms fail to recognize these as scholarly achievements. This observation has particular salience for the two Indigenous language scholars who are co-authors of this article.

In the face of these significant and important criticisms, Tymee-Clark (2004) calls for a "re-disciplining" of the disciplines, a stance that suggests an important emphasis on decolonization efforts throughout the academy. Pidgeon (2016) argued that this is critical if we are to move beyond tokenistic representations of some forms of Indigenous knowledge or curriculum themes rather than deeply integrated within the discipline, with an explicit naming of how dominant, Eurocentric forms of knowledge have been privileged. In the context of community-engaged scholarship, this argues for a re-conceptualization of what constitutes disciplinary recognition, but also involves finding ways to critically explore and make more visible Eurocentric biases and colonial foundations. It also calls for a revaluation of what matters and what counts, including work that revitalizes a community, such as language learning, participating in traditional land-based cultural activities or spiritual ceremonies that honour Indigenous epistemologies and ontologies. In this way, decolonizing the academy is simultaneously an act of restructuring and a support of political sovereignty and selfdetermination. While we hope that this work will transform post-secondary education so that it serves Indigenous and non-Indigenous communities alike, it may also bring to the fore critical discussions that consider the ultimate compatibility of these purposes.

\section{Our Stories}

As Thomas King (2003) so aptly stated, "The truth about stories is that is all we are" (p. 153). We want to tell you our stories because they will make clear how we understand ourselves, our work and the worlds we care so deeply and passionately about. We hope our stories will give voice to our experiences, and will make visible how particular assumptions and standards operate to constrain in unexpected and contradictory ways-in doing so, we hope this lays bare how much of the work which lies ahead requires making a new path, one not yet fully navigated among academic institutions. The Indigenous co-authors examples will highlight some of the tensions experienced by faculty members employed by a mainstream university while also situated as active members within our own Indigenous communities. Catherine's story as a settler Canadian and allied community-engaged scholar brings years of experience and a depth of understanding of a system that binds. 


\section{Trish's Story}

"Do you want tea? Do you want sugar? Do you want milk?" my student asks in Dene Zhatie. I respond with my small handful of Dene Zhatie words, "Eché, Íle, mąsi." We are outside by the fire where we're having class this week. I am the instructor of this second year level university course, and yet I am mostly silent, not wanting to disrupt the Dene Zhatie immersion space that we are working hard to create. My role is to support and guide the students in learning to speak and teach their language. I have arrived here with some knowledge about language learning and Indigenous language revitalization and while I have some credentials that have led to my assistant professor position, what the students appreciate most is my own experience as an adult learner of my mother's first language, Kwak'wala. With the community, we co-create the conditions for learning and co-construct new understandings about indigenous language revitalization.

"Edi tt'a azhí q'te?" I ask the student while I hold up my teacup. She responds, "Edi tt'a libó a $q^{\prime} t e$ " and I repeat the word she has given me for cup, "libó". I came into this course thinking I could teach language-learning methods by talking about them, but that is not working. I have to model the methods. I was scared to try to learn more than a few words alongside the students, scared that to begin to learn their language would disrupt what I believed to be the fragile state of learning my own language. But, I've committed to walk a journey with this community. I cannot arrive; deliver the content of my 1.5 credit course, and leave. We are on a learning path together.

I drink my tea while students and language mentors tend the fire, cook a meal, and prepare a moose hide for tanning. They are creating language immersion through real life activities. I wish I had the Dene Zhatie words to say, "Wow! How fortunate I am that this is my job." It is not lost on me what a privilege it is to work in such a cohesive way. There is strong continuity between my life path and my career path. There is continuity between what matters to me, what matters to the communities I work with, and what matters in my scholarship.

Like many of our Indigenous education programs, this program is delivered in community. We are teaching here, because our community partners tell us how important it is to bring the program to them. We are teaching here, because this is where the knowledge and the language live. The community leaders have told us that to start a program in a good way means we must start by building relationships, by connecting with place, and by being on the land.

There is more than meets the eye here. What is taking place around the fire goes beyond the course objectives to increase students' language proficiency and learning and teaching skills. It goes beyond the goal to work in partnership to contribute to the revitalization of the language of this community. As in the other Indigenous programs where I teach, we are engaged in a process of building new understandings that bridge the divide between Indigenous knowledge and the academy. We are exploring forms of teaching, learning and assessment that are meaningful to the community and hold the rigor required of higher education. In partnership, we are working to develop responsive education to meet community needs. Together we are engaged in a process of decolonization, creating space in the academy for Indigenous knowledge and community voice. We are making change so that the community can benefit 
from what the academy has to offer and the academy can benefit from the knowledge of the community.

I experience joy through the continuity that community-engaged scholarship brings to my work. I care deeply about the outcomes of our community-based programs, the lives of our students and the positive difference that what we are doing makes to Indigenous language revitalization. My intent is to work with Indigenous communities to co-construct useful and valued knowledge and understandings in response to community identified needs. In this process of collaborative work, there are no simple lines between the functions of teaching, research and service. For me, community-engaged scholarship means there is intersection and alignment between the work I do, who I am, and my relationship with community. While this continuity makes my scholarship meaningful, it also makes it challenging to provide evidence of my scholarship in a tenure and promotion process that requires reporting of academic activities in the separate categories of teaching, scholarship, and service.

\section{Onowa's Story}

Recently the Truth and Reconciliation Commission came to a close after five years of hearings, public events, and nation-wide witnessing. The final report included many calls to action, and these were taken up in social media venues in a variety of ways. One of my favourite actions was a grassroots Twitter campaign using the hashtag \#MyReconcilationIncludes, where the writer was invited to fill in the blank. Of course, many Indigenous peoples took this opportunity to express what meaningful reconciliation would look like to them but those that surprised me most were non-Indigenous Canadians who spoke up. It boosted my hopefulness about where this all might lead. It also got me thinking about what reconciliation means to me. Of course, one could make a mega-list across so many areas of an Indigenous life, supported and influenced by family and communities that have all been affected in various ways by the hard history of that which is now Canada. However, in my academic life, the list became very short. Simply, let me be me.

My reconciliation would include working for an institution of higher learning that does not judge or punish me for not being more European or 'white.' I would be allowed to smudge in my office. I would be allowed to teach without readings. I would be encouraged, celebrated and rewarded for the time I give in community, for the extra time it takes to build and maintain meaningful relationships in all the areas of my work. Where hugging was not strange, where every meeting started in prayer and food was offered. Where meetings were always face-toface, as equals, and never staring at someone's back or someone raised above the others at the front. Where we genuinely took an interest in each other's families, victories, and losses. Where generosity of spirit and humility are first and foremost. I have often remarked to my Indigenous colleagues, "Oh man, I think this place is making me white!" These thoughts come after moments when I lose my temper, when I forget to be kind first, when my humanity is taken over by frustration, when I buy into individualism (even for a moment), when I am asked/forced to compete for something, rather than serve my people.

The old saying "walking in two worlds" feels quite true a lot of the time, but yet, we 
don't really, do we? We are only really ever one person, living one life in one body. How can it be healthy to believe we could be so fractured? And if we try, what does it do to our spirit? As Indigenous scholars, we are often hired to assist with the project of "Indigenizing the academy" (Mihesuah \& Wilson, 2004). We are called, encouraged and supported to do this difficult heart and head work, sometimes in atmospheres of great resistance. However, when the time comes to do the "counting," Indigenization work is largely devalued. We are measured across three bars, yet two scarcely count (teaching and service), and within the lone remaining (scholarship), there is only one type of production that really matters- the golden egg- the peer-reviewed article. So, let's unpack that. Who are these peers? And why do they matter so much?

Recently I had a colleague share with me a story of submitting an article for publication on research she was doing with a First Nations immersion school. The article was rejected due to the sample size being too small. However, this is the only immersion school within the entire region of that province. This left her with the following conclusion... these are not my peers. The journal she chose was a top-tier journal, the kind that "counts," and, the kind with no Indigenous representation on the editorial board. I work in a department that prides itself in a shift away from "counting" and more towards depth, quality, and diversity of demonstrable influence due to the multi-disciplinary nature of the unit. Yet, following four years as a joint Senior Lecturer, and in a leadership position within our faculty, my time started to "count" when I shifted to an assistant professorship. Then my time came to be considered for reappointment, the first hurdle on the road to tenure. The feedback I received, while largely qualitative in its measurement with supportive narrative, was marked with specific numeric indicators of "too many" (graduate students) and "not enough" (peer-reviewed publications). Fast-forward now to a new Community-Engaged Scholarship (CES) policy recently added to our departmental criteria for tenure and promotion. A giant leap for humankind? A big step forward, yes, but the question yet untested is does this policy actually replace anything or is it simply an optional boost for those so inclined? Does this criteria offer an alternative to the traditional counting (even for those who publically denounce counting) or is it simply a nod to some of the "community-based" work many scholars are doing?

Only time will tell. But one can hope that recognizing CES is a recognition and acknowledgement that Indigenous and other communities are also our "peers" and at times our superiors (in the case of Elders), that these communities are partners, consumers of and collaborators with our work. If we truly are here to serve, to teach, to inquire, and to create new knowledge, then it must include all our peers, not just those within the walls of the academy.

\section{Catherine's Story}

Measuring change matters; indeed, for me, as a long time social justice activist and now a scholar in the field of social justice leadership, the importance of demonstrating how particular practices, processes, or policies can transform lives has become an essential characteristic of how I conduct research. In 2014, I was fortunate enough to be selected as the lead researcher 
who would inquire into the effectiveness of the Bachelor of Indigenous Language Revitalization (BEDLR) offered at the University of Victoria. I worked with an advisory group that consisted of faculty and staff, as well as Indigenous and non-Indigenous community members who had served as advisors to the program since its inception. The research design used culturallyinclusive evaluation practices, and included recognition of community protocols, ensuring that the voices of Elders were included and guided our reflective processes, and that our questions reflected the goals, priorities and perspectives of the two sponsoring Indigenous communities (WSÁNE'C and Kwagu’ł). This work also involved spending time in each of the communities, and a need to listen with an open heart, mind and spirit (Archibald, 2008) while continually acknowledging the deeply rooted forces of colonization that operate through processes of education and research.

Describing the full scale of the study goes beyond the scope of this article. However, the issues related to supporting and encouraging local language learning and processes of language revitalization, and the transformation of communities by lived language experiences were the strongest elements of the report. The stories I heard in community were powerful; I listened to the words of Elders, students, and instructors, each making evident at every turn the power of their language. As one Indigenous instructor said:

The language holds the people together and tells them what we belong to and are a part of... it will help us heal our past. It will help with our child rearing; it will help us to deal with the damage caused by residential schools to our people. Language is learning, learning that is relevant to our children and our communities.

Capturing the power, passion and experiences of these communities and the learning accomplished was difficult enough, but in the process of examining how the program operated in partnership between the university and community, I began to reflect more deeply on the nature, scope and depth of commitment this work required. I listened and learned about the ways in which faculty who managed the program, instructors who taught in it, and community members who supported students and family members gave deeply of themselves. I considered how their engagement in culturally accepted educational practices such as language apprenticeship, storying, intergenerational learning, land-based and ceremonial activities, and the relational practices of reciprocity and respect were much more than approaches to teaching and learning, but were core to their identities as Indigenous peoples. In typical research reports about program effectiveness, we frequently judge success by mapping the governance structures, listing policies that illuminate shared management, or counting the number of program graduates. Yet clearly the relationality inherent in the approaches taken in the BEDLIR program were built from a shared commitment to past, present and future generations of Indigenous peoples; such an ontological frame went well beyond any understandings typically used in program impact assessments. In the months since completing this report, and certainly in light of the literature reviewed for this article, I have been able to better understand the demands for a paradigm shift from Western to Indigenous 
frameworks for evaluating, measuring, and judging success. Without a doubt, the tenure and promotion policies and practices I've been familiar with as a Western academic — with its formulas that define teaching, service, scholarship_-are far too linear, too boundaried, and too narrowly imagined to adequately capture the scope and depth of the Indigenous community-engaged scholarship.

\section{Implications for Community-Engaged Scholarship: Theory and Practice}

Our stories, we believe, are powerful examples of the shifting tides of scholarship within engaged university settings. We know that many institutions across Canada are taking seriously the call to support Indigenous scholars and researchers, that they know of the stories we tell here and are looking to find ways that significantly alter systems, processes, or procedures known to penalize Indigenous academics, regardless of their fields of study. We know, for example, of the national partnership work of a consortium of universities in Canada. ${ }^{2}$ This group has made considerable progress towards mapping the scope of practice in Canada, has profiled developed and emerging best practices in communityengaged scholarship, and has focused considerable attention on how institutions might alter tenure and promotion practices in particular. Yet our stories, we believe, make evident several themes that deserve even greater attention by these groups.

First, we cannot, nor should not, subsume Indigenous community-engaged scholarship under the umbrella of community-engaged scholarship. In part, this is because, as LaVeaux and Christopher (2009) noted, Indigenous scholarship is far more than a thematic research area, but rather an entirely different paradigm, characterized by Indigenous ways of knowing, being and doing. If colonial orientations are to be dismantled then a genuine valuing of alternative epistemologies involves creating parallel recognition for Indigenous community-engaged scholarship protocols. We cannot continue to layer upon Indigenous colleagues the trappings of the standard ways of serving campus situated students: course readings, office hours, and publications in elite journals that do not address practitioner realities. But even addressing these issues goes only part of the way: the paradigm continues to honour expert knowledge holders as elites rather than community partners invested in shared, relationally built, culturally and spiritually sacred spaces. The academy requires a shift towards the embracing of Indigenous principles of learning, ontological beliefs about the holistic nature of transforming and becoming through experiential sites of shared engagement. Such an approach will look, feel, and enact itself in completely different ways than current systems of recognition do.

This means that we must not build layered systems, but rather we must replace one system with another: we imagine this system as one that provides choices or pathways

\footnotetext{
2 The consortium was formed in 2010; initiated by University of Guelph and the Community Campus Partnership for Health, several other institutions including Memorial University of Newfoundland, University of Alberta, University of Calgary, University of Regina, University of Victoria, University of Saskatchewan, and the Community Campus Partnerships for Health joined. The goal was to strategize and develop criteria and policy that would better support community-engaged scholarship in Canada.
} 
for Indigenous scholars to follow. Instead of measuring against a Western standard of performance that counts community-engaged Indigenous scholarship as an "add on" to the norms of academic performance that matter, these alternative pathways must have equal value and status within the institution. They are both legitimate and legitimized processes of recognition. It is only when this new standard is achieved that the Indigenous scholar will be able to move beyond their status as "native informants or Sherpas-unpaid guides who know the path, know the conditions, and can help us [Western scholars] navigate the treacherous paths to the top of the mountain where we will finally be able to see the truth laid out before us" (Thompson, 2004, p. 388).

Second, we believe that institutions must recognize they cannot be the sole arbiters of what constitutes a contribution to scholarship. The foundations of reciprocity, relationality, and respect, demand that we consider Indigenous communities as core partners in establishing principles of impact and significance. This also means that processes of consultation and engagement with Indigenous communities need to be core to designing and developing guidelines for policies that universities will use to judge scholarly importance and impact. This may also mean that the typical boundaries between service, teaching, and research would be blurred even more substantially; and that community judgments of impact considered on an equal footing with factors such as journal rankings or peer reviews.

Before concluding our article, we know that there are university communities and particular disciplines that may find these moves difficult to make; given this, we also believe that there are interim steps that could be taken that bridge between current tenure and promotion rules and alternative impact measurement tools such as those suggested here. For example, at the University of Victoria an effort is being made to create a directory of exemplary communityengaged scholars who can provide a more typical external review of an Indigenous engagedcommunity scholar, when requested to do so by an existing department or faculty. This would provide institutions with confidence that excellence and rigor is being maintained, even if the measures are not the same as for other scholars within a discipline. We see this as an active, doable and positive way forward that will provide that kind of alternative pathway that could be used in a transition to a very different model built on an Indigenous scholarly paradigm. Providing official recognition of Indigenous scholarship and research as part of the culture of institutional life is also an important way forward. We know of several Canadian universities who have developed and fund Indigenous Research Centers as a means of supporting Indigenous scholarship and research and these become safe places in which emerging and new Indigenous scholars can be formally and informally mentored and supported. Pidgeon (2016) also notes that a number of institutions are putting in place alternatives to the traditional bi-cameral governance models, ensuring that Elders and Indigenous leaders become part of the formal advisory and approval structures within the institution. These approaches invite Indigenous communities to be partners within, as well as collaborators and co-decision makers, essentially re-making institutional traditions. We think there is incredible value in moving forward in these ways; while we want and need serious system transformation, we recognize that many small steps like these move us incrementally towards our goals. 


\title{
Conclusion
}

We began our article with an imagined conversation, one that reflects the very real struggles we face as colleagues with life histories both inside and outside of the academy, and as change agents, each motivated to work in any way we can to make a difference in communities we care so deeply about. We know we have choices, and that we are privileged to do our work in the academy. We have attempted to show a way forward, a pathway that emerged from our lived experiences, while honouring the work of the many community-engaged scholars, university leaders, and community members who have begun to carve out a path by walking it. We suggested that it is possible to embrace tools that better enable the principles of reciprocity and respect to systems of assessing scholarship. We think many of the incremental policy steps outlined in this article are important ways to shift away from privileging certain conceptions of research, and we applaud those engaged in this work because it is shifting practice in important ways. However, we still hold that Indigenous scholarship has unique features, impacts and perspectives that deserve specific attention. We need community-engaged scholars and their allies to continue to argue for diverse and emergent approaches to evaluating and assessing Indigenous scholarship because local cultural and community perspectives must be valued and become embedded as vital features of institutional systems. It is through these efforts that we can celebrate our shared commitment and deeply held beliefs in the power of research to alter lives and communities in powerful ways.

\begin{abstract}
About the Authors
Catherine McGregor (corresponding author) is a leadership scholar who is particularly interested in the role leaders play in enabling socially just and transformational change. A particular area of interest is the idea of allyship: an inclusive, relationally informed stance focused on shared enactment. Catherine currently serves as Associate Dean in the Faculty of Education. Email: cmcgreg@uvic.ca
\end{abstract}

Onowa McIvor is maskiko-nihiyaw (Swampy Cree) and Scottish-Canadian. Her Cree family is from Norway House in Manitoba. She is also an assistant professor in Indigenous Education at the University of Victoria. Onowa's research focuses on Indigenous language revitalization, sociocultural aspects of language learning; second language acquisition; and cultural identity development.

Trish Rosborough (corresponding author) is from the Kwakiutl Nation on Vancouver Island. She is an assistant professor of Indigenous education at the University of Victoria. Trish's research area and life passion are Indigenous language revitalization. She is an adult learner and speaker of her mother's first language, Kwak'wala. 


\section{References}

Archibald, J. (2008). Indigenous storywork: Educating the heart, mind, body and spirit. UBC Press: Vancouver.

Barreno, L., Elliott, P., Madueke, J., \& Sarny, D. (2013). Community Engaged Scholarship and faculty assessment. A review of Canadian Practices. Report prepared for Faculty Assessment Workgroup: University of Regina. Retrieved from: engagedscholarship.ca/wp-content/ uploads/2014/10/Faculty-Assesment-Paper1.pdf

Battiste, M. (2002). Indigenous knowledge and pedagogy in First Nations education: A literature review with recommendations. A report prepared for the National Working Group on Education and the Minister of Indian Affairs. Retrieved from: http://www.afn.ca/uploads/files/education/24._2002_oct_marie_battiste_ indigenousknowledgeandpedagogy_lit_review_for_min_working_group.pdf

Carnegie Community Engagement Classification (2015). Retrieved from: http://nerche.org/index. php?option $=$ com_content\&view $=$ article\&id $=341 \&$ Itemid $=92$

Cavender-Wilson, A. (2004). Re-claiming our humanity: Decolonization and the recovery of Indigenous knowledge. In D. A. Mihesuah \& A. Cavender Wilson (Eds.), Indigenizing the academy: transforming scholarship and empowering communities (pp. 69-87). Lincoln \& London: University of Nebraska Press.

Deloria, Jr. V. (2014). Marginal and sub marginal. In D. A. Mihesuah \& A. Cavender Wilson (Eds.), Indigenizing the academy: transforming scholarship and empowering communities (pp. 16-30). Lincoln \& London: University of Nebraska Press.

Ellingson, L., \& Quinlan, M. (2012). Beyond the research/service dichotomy: Claiming all research products for hiring, evaluation, tenure and promotion. Qualitative Communication Research, 1(3), 385-399.

Gaudry, A. (2015). Researching the resurgence: Insurgent research and community engaged methodologies in $21^{\text {st }}$ century academic inquiry. In L. Brown \& S. Strega (Eds.), Research as resistance (pp. 243-267). Toronto: Canadian Scholars Press.

Jackson, E. (2014). Community-university engagement in Canada: Voices from the field. Report to President and Provost, McMaster University. Retrieved from http:/ / macconnector.mcmaster.ca/docs/ default-source/default-document-library/ce_voices.pdf?sfvrsn $=0$

Jordan, C. (2007). Community-engaged scholarship review, promotion \& tenure package. Peer Review Workgroup, Community-Engaged Scholarship for Health Collaborative, CommunityCampus Partnerships for Health. Retrieved from https://depts.washington.edu/ccph/ pdf_files/CES_RPT_Package.pdf

King, T. (2003). The truth about stories: A native narrative. Toronto: Canadian Broadcasting Corporation.

LaVeaux, D., \& Christopher, S. (2009). Contextualizing CBPR: Key Principles of CBPR meet Indigenous research context. Pimatisiwin, 7(1), 1-18.

Unnamed author. (2015). Nano'ke'sila “Contemplating”: Bachelor of Education in Indigenous Language Revitalization: Honouring, respecting and celebrating Indigenous language learning. An evaluation study. Unnamed university.

Metzer, J. \& Szekeres, S. (n.d.). The scholarship of engagement. A report to Nazareth College. Retrieved from bttps:/ / wmw2.naz:edu/ files/8914/0924/4341/Engaged20scholarship.pdf

Mihesuah, D. A. \& Wilson, A. C. (2004). Introduction. In D. A. Mihesuah \& A. Cavender Wilson (Eds.), Indigenizing the academy: Transforming scholarship and empowering communities (pp. 1-15). University of Nebraska Press: USA. 
Mihesuah, D. A. (2004). Academic gatekeepers. In D. A. Mihesuah \& A. Cavender Wilson (Eds.), Indigenizing the academy: transforming scholarship and empowering communities (pp. 31-47). Lincoln \& London: University of Nebraska Press.

Pidgeon, M. (2016). More than a checklist: Meaningful Indigenous inclusion in higher education. Social inclusion, 4(1) 77-91.

Scott, J. (2007). Engaging academia in community research: Overcoming obstacles and providing incentives. Report prepared by the Centre for Urban and Environmental Solutions at Florida Atlantic University. Retrieved from: http://consensus.fsu.edu/bog-fcrc/pdfs2/Engaging_Academic_ in_Community_Research_FAU.doc

Thompson, A. (2004). Anti-racist work zones. In K. Alston (Ed.), Philosophy of education yearbook (pp. 387-395). Urbana Champaign, IL: Philosophy of Education Society.

Tyeeme Clark, D. A. (2004). Not the end of the stories, not the end of the songs: Visualizing, signifying, counter-colonizing. In D. A. Mihesuah \& A. Cavender Wilson (Eds.), Indigenizing the academy: Transforming scholarship and empowering communities (pp. 218-232). Lincoln \& London: University of Nebraska Press.

Wenger, L., Hawkins, L., \& Seifer, S. (2012). Community engaged scholarship: Critical junctures in research, practice, and policy. Journal of Higher Education Outreach and Engagement, 16(1), 171 181. 